Dept. of Zoology,

Fac. of Science, South Valiey University, Sohag, Egypt.

\title{
SARCOPLASMIC RETICULUM, SARCOLEMMA, CALCIUM AND CARDIAC FORCE \\ IN THE CATFISH AND FROG
}

(With 1 Table and 8 Figures)

By

M.F. EL-SAYED

(Received at 29/5/2001)

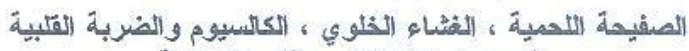

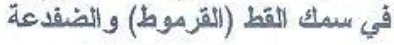

$$
\text { محس فرج الصبيد }
$$

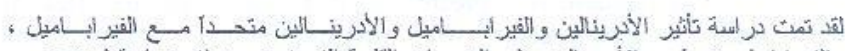

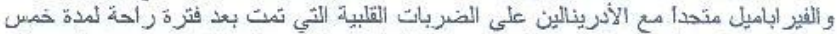

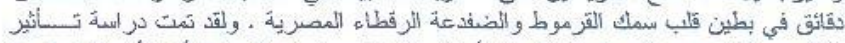

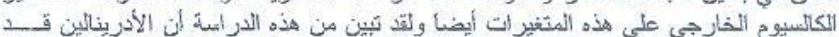

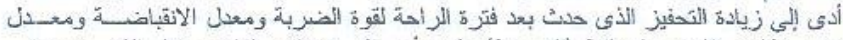

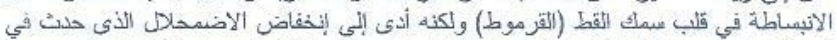

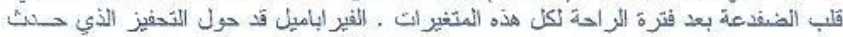

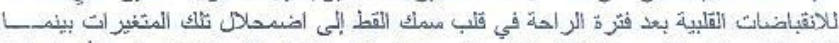

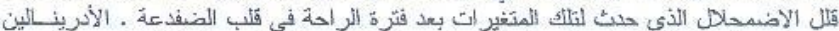

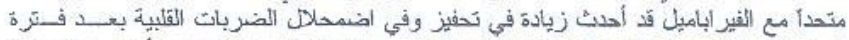

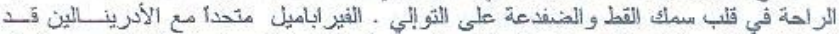

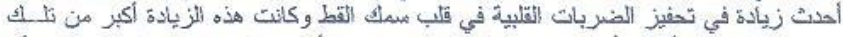

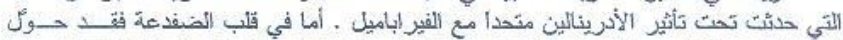

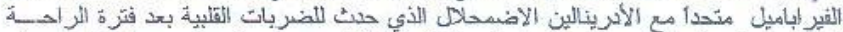

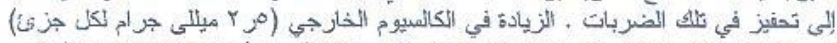

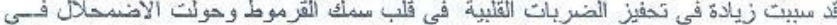

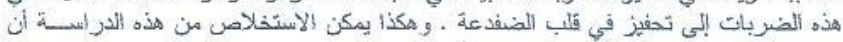

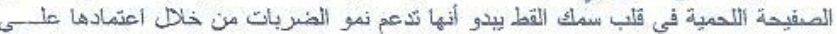

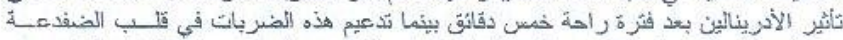

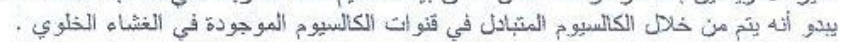




\section{SUMMARY}

The influences of adrenaline, verapamil, adrenaline combined together with verapamil and verapamil combined together with adrenaline on the cardiac contractions developed after 5 minutes of rest in the ventricular tissues of the catfish (Clarias gariepinus) and frog (Bufo regularis) werc studicd. The effect of extracellular calcium on the cardiac contractions was also investigated. Adrenaline led to an increase in the rest potentiation and to a decrease in the rest decay of force, rate of contraction $(\mathrm{df} / \mathrm{dt})$ and the rate of relaxation $(-\mathrm{df} / \mathrm{dt})$ developed after 5 minutes of rest in the myocardium of the catfish and frog, respectively. Verapamil transformed the post-rest potentiation of contractions into a post-rest decay in the myocardium of catfish whereas; it decreased the post-rest decay in the myocardium of frog. Adrenaline combined together with verapamil increased the post-rest potentiation and the postrest decay of contractions in the myocardium of the catfish and frog respectively. Verapamil combined together with adrenaline increased the post-rest potentiation of contractions in the myocardium of the catfish. However, this increase was greater than that caused under the effect of adrenaline combined together with verapamil. In the frog myocardium, verapamil combined together with adrenaline transformed the post-rest decay of contractions into a post-rest potentiation. Increased extraccllular $\mathrm{Ca}^{2+}(2.5 \mathrm{mM})$ caused an increase in the post-rest potentiation of contractions in the catfish myocardium and transformed the post-rest decay of contractions into a post-rest potentiation in the frog mycardium Thus, it can be concluded that the cardiac sarcoplasmic reticulum of the catfish seems to support force development during adrenaline dependent after rest intervals, whereas the cardiac sarcolemmal $\mathrm{Ca}^{2-1}$ channels appears to have a role in the force developed after 5 minutes of rest in the frog heart.

Key Words: Sarcoplasmic Reticulum, Sarcolemma, Adrenaline, Verapamil, Cardiac force, Catfish, Frog.

\section{INTRODUCTION}

Excitation-contraction (E-C) coupling and calcium cycling in cardiac muscle are, as yet, poorly understood. This is due, in part, to the lack and limitation of specific agents that inhibit or interfere with the specific mechanisms involved in $\mathrm{Ca}^{2+}$ movements. It has been reported 
that there are two major sources of $\mathrm{Ca}^{2+}$ that can participate in $\mathrm{E}-\mathrm{C}$ coupling namely SR Ca ${ }^{2+}$ release and sarcolemmal Ca ${ }^{2+}$ influx (Macleod and Bers, 1987). Knowledge of the precise mechanisms of action of the agents, which stimulate or inhibit these two sources, is crucial to their use in understanding of $\mathrm{E}-\mathrm{C}$ coupling.

In cardiac muscle, ryanodine specifically inhibits the function of the SR by interfering with the opening of its $\mathrm{Ca}^{2+}$ channels (Gesser, 1996). Ryanodine also increases $\mathrm{Ca}^{2+}$ accumulation by Cardiac SR (Jones et al., 1979). Ryanodine may also increase a leak of calcium from the SR (Hilgemann et al., 1983). Meissner (1986) has also reported that ryanodine can either block or enhance $\mathrm{Ca}^{2+}$ loss from isolated SR vesicles depending on specific conditions. In the catfish ventricular tissue, the post-rest potentiation of the cardiac force increased with increasing rest periods. Thesc post-rest potentiations were removed by $10 \mu \mathrm{M}$ ryanodine (El-Sayed, 1994a). After a long rest period, the SR is depleted of calcium, but resumption of stimulation will increase $\mathrm{Ca}$ influx and progressively refill the SR. This will require net movement of $\mathrm{Ca}^{2+}$ from the extracellular space into the cell and will decrease the extracellular calcium (Macleod and Bers, 1987). Hilgemann et al. (1983) used extracellular $\mathrm{Ca}$-sensitive absorption dyes and found that ryanodine increased the magnitude of the extracellular $\mathrm{Ca}^{2+}$ depletions induced by post-rest stimulation. These results were interpreted to suggest that the $\mathrm{SR}$ became more depleted of $\mathrm{Ca}^{2+}$ during rest due to a leak in the SR membrane induced by ryanodine. These results suggest that ryanodino may inhibit $\mathrm{SR} \mathrm{Ca}{ }^{2+}$ release and/or accelerate the loss of $\mathrm{SR} \mathrm{Ca}^{2+}$ responsible for the post-rest decay.

The role of the SR in the cardiac E-C coupling secms to vary among ectothermic vertebrates (Tibbits et al., 1991; Driedzic and Gesser, 1994). It is probably small in frog (El-Sayed, 2000 a) but significant in tuna atrial tissue (Keen et al., 1992). The cardiac SR of the catfish appears to be functionally more developed than that of the frog myocardium (El-Sayed, $2000 \mathrm{~b}$ ). Isolated ventricular tissue of the catfish differs from that of frog in displaying a negative force-frequency relationship, particularly evident as a post rest potentiation, which is strongly reduced by ryanodine (El-Sayed, 1994a). In the catfish ventricular tissue, the post-rest potentiation and its sensitivity to ryanodine are influenced by temperature (El-Sayed, 1994a). The function of myocardial SR in living catfish is unclear, however, irrespective of temperature, it does not seem important at stable pacing frequencies within the physiological stimulation range (El-Sayed, 
2000a). Studies on frog suggest that the cardiac SR may function as a mediator for different hormones and hormone-like substances (Niecergerke and Page, 1989). In this respect, adrenaline is of obvious interest. It stimulates myocardial contractions (Brückner et al., 1985). In mammalian cardiac muscle, adrenaline increases the $\mathrm{Ca}^{2+}$ uptake and release by the SR and then it activates the function of the SR (Boller and Bott, 1989). Adrenaline also increases the cellular calcium uptake in poikilothermic vertcbrates such as flounder (Lennard and Huddart, 1989). Adrenaline may affect $\mathrm{Na}^{+}-\mathrm{Ca}^{2+}$ exchange and consequently the amount of $\mathrm{Ca}^{2+}$ entering across the sarcolemma during excitation, of released by the intracellular storcs, like the $\mathrm{SR}$. This is due to the fact that adrenaline is known to stimulate the $\mathrm{Na}^{+}-\mathrm{K}^{+}$purnp (Pecker et al. 1986). In the myocardium of the catfish, adrenaline slightly increases the contractions developed after 5 minutes of rest suggesting that the SR may contribute in the regulation of the cardiac force at low rates of stimulation. In the frog myocardium adrenaline decreases the post-rest decay of contractions at the stimulation rate of $0.003 \mathrm{~Hz}$ indicating that the sarcolemmal $\mathrm{Ca}^{2+}$ fluxes may support the cardiac contractions developed after rest intervals (El-Sayed, 2000 a).

It is generally believed that the sarcolemmal $\mathrm{Ca}^{21}$ influx plays a kcy role in the excitation-contraction coupling. In cteleost heart, contraction is though to depend more on $\mathrm{Ca}^{2+}$ fluxes across the sarcolemma at pacing rates of stimulation (Morad and Cleemann, 1987). Tibbits et al. (1990) suggested that the transsarcolemmal Ca ${ }^{2+}$ fluxes are a major mediator of the beat-to-beat regulation of cytosolic $\mathrm{Ca}^{2+}$ concentration in the salmonid heart. The catfish myocardium exhibits rest potentiation of force after rest intervals of more than $30 \mathrm{~s}$ (El-Sayed, 1994a). Verapamil, which inhibits the sarcolemmal Ca ${ }^{2+}$ transport (Devlin, 1993) inhibits this rest potentiation indicating that the sarcolcmmal $\mathrm{Ca}^{2+}$ influx may contribute to rest potentiation (El-Sayed, 2000 a).

The myocardium of the frog exhibited a positive staircase i.e, the cardiac force increases with the increasing of the stimulation rates (Driedzic and Gesser, 1985). Furthermore the frog ventricular tissue exhibits post-rest decay of force after 5 minutes of rest (El-Sayed, 2000 a), a phenomenon that relies on the $\mathrm{Ca}^{2+}$ transported through the sarcolemmal $\mathrm{Ca}^{2+}$ fluxes. Verapamil, an inhibitor of the sarcolemmal $\mathrm{Ca}^{2+}$ channel, decreased this post-rest decay (El-Sayed, $2000 \mathrm{a}$ ).

The calcium necessary to support the cardiac contraction in most ectothermic animals is derived from the extracellular space (Morad and 
Cleemann, 1987). The sarcolemmal $\mathrm{Ca}^{2-1}$ channel mediates the transport of calcium from the extracellular space (Reuter, 1983) and this calcium is responsible for the activation of the contractile system and thereby the cardiac contractions. Thus, the verapamil action may involves an inhibition of this transsarcolemmal calcium influx via the $\mathrm{Ca}^{2+}$ channel.

The aim of the present study was to evaluate the rest-potentiation of contractions in the catfish (Clarias gariepinus) myocardium and restdecay of cardiac contractions in the frog heart (Bufo regularis) with respect to SR and sarcolemma dependence and influences of the interactions between adrenaline and verapamil.

\section{MATERIALS and METHODS}

Animals:

Catfish (Clarias gariepinus) of both sexes were obtained from a canal near to Sohag City and held in fresh water tanks at $10-15^{\circ} \mathrm{C}$. Frogs (Bufo regularis) were kept in terraria with the possibility to dwell in water. These animals were fed regularly. Both animals were collected during June and July.

\section{Experimental Preparations:}

Ventricular preparations of approximately $1 \mathrm{~mm}$ diameter were mounted for isometric recording of contractions as previously described (El-Sayed, 2000 a). The preparations were initially stimulated at 12 contraction $\min ^{-1}$ and stretched until Peak force did not increase any further. After stabilization at $0.2 \mathrm{~Hz}$ for about 30 minutes, each preparation was exposed to resting period of 5 minutes.

\section{Bathing medium:}

The bathing medium for the hearts of the catfish and frog consisted of (in $\mathrm{mM}$ ): $\mathrm{NaCl} 125, \mathrm{KCl} 2.5, \mathrm{CaCl}_{2} 1.25, \mathrm{Mg} \mathrm{SO} \mathrm{SO}_{4} 0.94$, $\mathrm{NaH}_{2} \mathrm{PO}_{4}$ 1, $\mathrm{NaHCO}_{3} 15$ and glucose 5 . The medium was equilibrated with $1 \% \mathrm{CO}_{2}$ and $99 \% \mathrm{O}_{2}$ by gas mixing pump (Wösthoff $1 \mathrm{M} 301 / \mathrm{af}$ ). The $\mathrm{pH}$ of the media for both animal was 7.5. The experimental temperature was $20 \pm 0.5$ (Cole-parmer OT 286/16, USA),

Drugs:

Both adrenaline-tartrate (Sigma) and verapamil (Sigma) were cach dissolved in distilled water to $10 \mathrm{~m} \mathrm{~mol} / \mathrm{L}^{-1}$ and kept frozen $\left(-20^{\circ} \mathrm{C}\right)$ in suitable portions.

Experimental protocol:

Two independent experiments were conducted. The first experiment was conducted to evaluate the influence of adrenaline, 
verapamil and adrenaline combined together with verapamil on the cardiac contractions (Force, rate of contraction " $\mathrm{df} / \mathrm{dt}$ ", rate of relaxation "-df/dt") and time to peak tension "TPT" of both catfish and frog devcloped after 5 minutes of rest. Four preparations from each ventricles were run in parallel at a frequency of $0.2 \mathrm{~Hz}$ for about 30 minutes. After stabilization, the first strip was exposed to adrenaline, the second strip was exposed to verapamil, the third strip was exposed to adrenaline for about 10 minutes, then it was subjected to verapamil, whereas the fourth strip served as control in both animals. Five to ten minutes later, the stimulation rate of $0.2 \mathrm{~Hz}$ was interrupted by 5 minutes of rest with one concluding stimulation. In the second experiment, the above experimental protocol was repeated except the third strip was subjected to verapamil first, then it was exposed to adrenaline, in both animals also. After these changes, the four strips in both experimental protocols were exposed to $2.5 \mathrm{mM}$ extracellular calcium.

Data analysis:

The changes imposed by different treatments were normalized as a percentage $(\%)$ to that stabilized at a frequency of $0.2 \mathrm{H} z$ before addition of any treatments.

Data are expressed as means \pm S.D. The significance level was set to 0.05 .

\section{RESULTS}

The contractions developed after 5 minutes of rest have previously described in the myocardium of the catfish and frog (E1Sayed, 2000 a). The effects of adrenaline and verapamil on the restpotentiation and the rest-decay were also studied in the ventricular tissue of the catfish and frog (El-Sayed, 2000 b). It was important to reinvestigate their influences in this work to serve as a control for the effect of adrenaline combined together with verapamil.

Adrenaline and cardiac contractions:

Relative to the stimulation rate of $0.2 \mathrm{~Hz}$, adrenaline increased and decreased the rest-potentiation and the rest decay of the cardiac force in the catfish and the frog, respectively (Fig. 1 and 2). Increasing cxtracellular $\mathrm{Ca}^{2+}$ from 1.25 to $2.5 \mathrm{mM}$ led to a greater increase in the rest-potentiation of force under the effect of adrenaline than that of the control in the myocardium of the catfish (Fig. 1 and Table A). But it removed the post-rest decay of force and transformed it into a post-rest potentiation in the myocardium of frog (Fig. 2 and Table B). Moreover, 
the post-rest potentiation of force as a result of increasing extracellular $\mathrm{Ca}^{2-}$ was higher with adrenaline than that with the control (Fig. 2 and Table B).

As shown in Fig. 3,4 and Table A, B, adrenaline increased the rest-potentiation and the rest-decay in the rate of contraction $(\mathrm{df} / \mathrm{dt})$ of the catfish and the frog myocardium, respectively. Increased extracellular $\mathrm{Ca}^{2+}(2.5 \mathrm{mM})$ increased the post-rest potentiation of $\mathrm{df} / \mathrm{dt}$ in the myocardium of the catfish to a value higher than that of control (Fig. 3 and Table A). However, it transformed the post-rest decay of $\mathrm{df} / \mathrm{dt}$ in the myocardium of the frog into a post-rest potentiation (Fig. 4 and lable B).

Adrenaline increased the rest-potentiation of the rate of relaxation (-df/dt) in the catfish myocardium (Fig. 5 and Table A), whereas it slightly decreased the -df/dt in the myocardium of the frog (Fig. 6 and Table B). Like that of df/dt, $2.5 \mathrm{mM}$ extracellular $\mathrm{Ca}^{2}$ increased the rest-potentiation of the cardiac -df/dt in the catfish (Fig. 5 and Table A) and transformed the rest-decay in the cardiac-df/dt of the frog into rest-potentiation (Fig. 6 and Table B).

As illustrated in Figs. $7 ; 8$ and Table A; B, adrenaline slightly increased and removed the rest-potentiation and the rest-decay in the time to peak tension (TPT) in the myocardium of the catfish and the frog, respectively. The rest-potentiation of TPT was increased by 2.5 $\mathrm{mM} \mathrm{Ca}{ }^{2+}$ in the catfish heart (Fig. 7 and Table A), whereas the removal of TPT with adrenaline was transformed into rest-potentiation by 2.5 $\mathrm{mM} \mathrm{Ca}{ }^{2+}$ in the frog heart (Fig. 8 and Table B).

Verapamil and Cardiac Contractions:

In the myocardium of the catfish, verapamil transformed the post-rest potentiation of force (Fig. 1), of the rate of contraction (Fig. 3), of the rate of relaxation (Fig. 5) and of the time to peak tension (Fig. 7) into a post-rest decay. These post-rest decays of contractions and of the time to peak tension was transformed into a post-rest potentiation in the presence of $2.5 \mathrm{mM} \mathrm{Ca}^{2+}$ (Figs. 1, 3,5 and 7; and Table A). But, in the myocardium of the frog, verapamil decreased the post-rest decay of contractions and of the time to peak tension (Figs. 2, 4,6 and 8, and Table B). As in the myocardium of the catlish, $2.5 \mathrm{mM}$ extracellular $\mathrm{Ca}^{2+}$ transformed these post-rest decays into post-rest potentiations.

Adrenaline Combined Together With Verapamil and Cardiac Contractions:

The results presented suggest that the post-rest potentiation, and in particular its stimulation by adrenaline in the catfish myocardium, 
depends on the SR. So, it was important to investigate the role of the sarcolemmal $\mathrm{Ca}^{2+}$ channel in the E-C coupling after activation of SR function by adrenaline. This was examined in separate series of experiments in which adrenaline was added first for ten minutes then, the ventricular preparation was exposed to verapamil. Adrenaline combined together with verapamil led to an increase in the post-rest potentiation of the cardiac force (Fig. 1), of the df/dt (Fig. 3) of the df/dt (Fig. 5) and of the TPT (Fig. 7). These post-rest potentiation of contractions and of TPT was increased by $2.5 \mathrm{mM}$ extraccllular $\mathrm{Ca}^{2-}$ (Figs. 1, 3, 5 and 7 , and Table $A$ ).

The present results suggest also that the sarcolemmal $\mathrm{Ca}^{2+}$ channel may have a role in the cardiac E-C coupling of the frog. This is because the myocardium of the frog exhibited a post-rest decay of contractions after rest intervals and verapamil only decreased this restdecay of contractions. So, it was necessary to examine the role of the SR in the regulation of force by stimulating its activity with adrenaline. Like that of the catfish cardiac muscle, the ventricular preparation of the frog was subjected first to adrenaline for 10 minutes then verapamil was added. Adrenaline combined together with verapamil caused an increase in the rest-decay of force (lig. 2), a decrease in the rest decay of the rate of contraction (Fig. 4) and an increase in the rest decay of the rate of relaxation (Fig. 6). Adrenaline combined together with verapamil decreased the post-rest potentiation of time to peak tension (Fig. 8). The post-rest decay of force (Fig. 2) of df/dt (Fig. 4) and of - df/dt (Fig. 6) was transformed into a post-rest potentiation by $2.5 \mathrm{mM}$ extracellular $\mathrm{Ca}^{2+}$. Also, $2.5 \mathrm{mM} \mathrm{Ca}^{2+}$ increased the post-rest potentiation of TPT (Fig. 8 and Table B).

Verapamil Combined Together With Adrenaline and Cardiac Contractions:

It might be asked if the described effects of adrenaline combined together with verapamil on the contractions and on the TPT developed after 5 minutes of rest in the myocardium of the catfish and the frog may depend on the sarcolemmal $\mathrm{Ca}^{2+}$ channel. This seems not be the case, as scen in Fig. 1 to Fig. 8 and Table A and B, depicting the results of another series of experiments, which are similar to those of adrenaline combined together with verapamil except that verapamil was added first to inhibit the sarcolemmal $\mathrm{Ca}^{2+}$ channel, then the ventricular preparations were exposed to adrenaline to stimulate the intracellular $\mathrm{Ca}^{2+}$ uptake by the SR. Verapamil combined together with adrenaline led to a greater increase in the post-rest potentiation of the cardiac force 
(Fig. 1), of the rate of contraction (Fig. 3), of the rate of relaxation (Fig. 5) and of the time to peak tension (Fig. 7) in the catfish. However, verapamil combined together with adrenaline transformed the post-rest decay of force (Fig. 2), of the rate of contraction (Fig. 4), of the rate of relaxation (Fig. 6) and of the time to peak tension (Fig. 8) into a post-rest potentiation in the myocardium of the frog. Increased extracellular $\mathrm{Ca}^{2+}$ $(2.5 \mathrm{mM})$ led to an increase in the increased post-rest potentiation of contractions and the time to peak tension which caused as a result of application of verapamil combined together with adrenaline in the myocardium of the catfish and the frog (Figs. 1-8 and Table A and B)

\section{DISCUSSION}

The release of stored $\mathrm{Ca}^{2+}$ from the sarcoplasmic reticulum is suggested not to be a major feature of the excitation contraction coupling in the teleost heart and the $\mathrm{Ca}^{2+}$ used to activate the tropomyosin is predominantly of extracellular origin (Vomanen, 1989; Tibbits et al, 1990). The most compelling evidence for this assertion is the lack of an effect of ryanodine on contraction development. Ryanodine is a plant alkaloid, which affects the SR calcium release channel such that the SR can not supply $\mathrm{Ca}^{2+}$ for tension development (Sutko and Kenyon, 1983). Ryanodine does not affect tension development in isolated ventricular strips from fish under conditions, which approximate those assumed to exist in vivo (El-Sayed and Gesser, 1989). However, Ryanodine inhibits the post-rest potentiation of force in the ventricular preparations of the catfish suggesting that the SR may contribute in the regulation of the cardiac force developed at the low rates of stimulation (El-Sayed, 1994a). These findings agrec with the functional evidence that the SR is well developed in the ventricular tissue of the catfish (El-Sayed, 1994b). At a steady pacing rate of stimulation, adrenaline enhances the cardiac force in the atrial and ventricular tissues of rainbow trout. This effect was not removed by ryanodine (Gesser, 1996), and seems not to depend on the sarcoplasmic reticulum (SR). The situation was different when the steady state of stimulation was interrupted by 5 minutes of rest in the catfish myocardium (El-Sayed, 2000 a). As in mammalian cardiac tissue (Drake-Holland et al., 1992), adrenaline enhanced the post-rest potentiation of contractions and time to peak tension in the catfish ventricular tissue. This action of adrenaline seems to involve the activation of the SR, as it was not removed by the interaction between 
adrenaline and verapamil which is known to inhibit the $\mathrm{Ca}^{2+}$ transport via the sarcolemmal $\mathrm{Ca}^{2+}$ channel (Godfraind, 1987).

$\Lambda$ s cited above, the $\mathrm{Ca}^{2+}$ uptake by the cardiac SR is not the only source for activation of the contractile proteins but also the extracellular $\mathrm{Ca}^{2+}$ which flux through the sarcolemmal $\mathrm{Ca}^{2+}$ channels used to support the contractility in most ectothermic animals. The cardiac sarcolemma of the teleost is sparsely developed compared with that of mammals according to ultrastructural studies (Gabella, 1978). Verapamil, a tertiary aminc, is usually used as an inhibitor of the sarcolemmal $\mathrm{Ca}^{2+}$ channels (Murad, 1991). Verapamil had a negative inotropic effect on the contractions of the mammalian hearts (Ponce-Hornos et al., 1990) in which the excitation-contraction coupling is highly SR dependent (Stemmer and Akera, 1986). In the catfish myocardium, verapamil inhibited the post-rest potentiation of contractions developed after 5 minutes of rest and of the time to peak tension (El-Sayed, $2000 \mathrm{a}$ ). Here it can be suggested that the sarcolemmal $\mathrm{Ca}^{2+}$ channel have a role in the excitation-contraction coupling in the myocardium of the catfish. But, this negative inotropic effect of verapamil on the contractions was removed by addition of adrenaline after exposing the ventricular tissue to verapamil. In another mcaning, the interaction between verapamil and adrenaline removed the negative inotropic effect of verapamil and transformed the post-rest decay of contractions into a post-rest potentiation. Thus, it can be concluded that the cardiac excitationcontraction coupling in the catfish is mainly SR dependent at the lower rates of stimulation $(0.003 \mathrm{~Hz})$. However the finding that the positive inotropic effect of adrenaline combined together with verapamil on contractions is lower than that of verapamil combined together with adrenaline indicate that the sarcolemmal $\mathrm{Ca}^{2+}$ channels may have a role in supporting the force developed after 5 minutes of rest in the myocardium of the catfish (Clarias gariepinus).

The frog ventricular tissue showed a post-rest decay of force when the steady pacing rates was interrupted by 5 minutes of rest. This post-rest decay of force was increased by caffeine, an inhibitor of the SR function, (El-Sayed, 2000 a). Moreover, the frog heart muscle exhibited a positive staircase (Driedzic and Gesser, 1985). These findings arc believed to reflect an involvement of the sarcolemmal $\mathrm{Ca}^{2+}$ fluxes in the excitation-contraction coupling. In agreement with this suggestion, adrenaline which is known to stimulate the activity of the SR by increasing the amount of calcium circulating within the intercellular stores ;SR: (Morad and Goldman. 1973) decreased this post-rest decay 
of contractions. Also, verapamil which is generally used to block the inward calcium current through the sarcolemmal $\mathrm{Ca}^{2+}$ channel did not remove the negative inotropic effect of rest interval ( 5 minutes) on the cardiac contractions of the frog heart muscle. Furthermore, it has been reported that in frog ventricular muscle $\mathrm{Ca}^{2+}$ for activation of the contractile system is transported primarily from the extracellular space (Klitzner and Morad, 1983). However, it has been suggested that the sarcoplasmic reticulum seems to play an important role in $\mathrm{Ca}^{2+}$ cycling in frog myocardium exposed to rest intcrval of $60 \mathrm{~s}$. (Anderson et al, 1989). Here, it can be speculated that verapamil impaired the transport of extracellular $\mathrm{Ca}^{2+}$ via the cell membrane by inhibiting the sarcolemmal $\mathrm{Ca}^{2+}$ channels, and adrenaline, in spite of its stimulatory effect on the $\mathrm{Ca}^{2+}$ cycling within the intercellular store (SR) in the mammalian cardiac muscle (Drake-Holland et al., 1992) can not able to remove the negative inotropic effect of rest interval on contractions. Thus, the excitation-contraction coupling in the frog myocardium seems to be sarcolemmal $\mathrm{Ca}^{2+}$ dependent. However, the situation was different when the ventricular tissue of frog was exposed first to verapamil and after that adrenaline was added to the muscle bath. This interaction between verapamil and adrcnaline transformed the post-rest decay of contractions into a post-rest potentiation. This action may involve an activation of SR by adrenaline, as it decreased the post-rest decay of contractions in the absence of verapamil. However, it is still unclear why the post-rest decay of contractions is transformed to a post-rest potentiation when verapamil was added to the ventricular preparation of frog before adrenaline. It is possible that the present experiments are too crude to detect the influx changes due to a slow leakage of $\mathrm{Ca}^{2}$ from the SR induced by adrenaline

To conclude, it appears that the cardiac SR of the catfish can participate in the E-C coupling at subphysiologically heart rate. This conclusion is strengthened by the findings that adrenaline, which is known to increase the $\mathrm{Ca}^{2+}$ sequestration in the $\mathrm{SR}$, adrenaline combined together with verapamil and verapamil combined together with adrenaline led to an increase in the post-rest potentiation of contractions. Transsarcolemmal $\mathrm{Ca}^{2+}$ channel may also have a role in the $\mathrm{E}-\mathrm{C}$ coupling of the catfish heart as verapamil transformed the post-rest potentiation of contractions into a post-rest decay and as this negative inotropic effect of verapamil was removed by increased extracellular $\mathrm{Ca}^{2+}(2.5 \mathrm{mM})$. However, in frog ventricular tissuc, the $\mathrm{E}-\mathrm{C}$ coupling is mainly dependent on the transsarcolemmal $\mathrm{Ca}^{2+}$ influx at 
suphysiologically rates of stimulation as verapamil, an inhibitor of the sarcolemmal $\mathrm{Ca}^{2+}$ channel, and adrenaline combined together with verapamil did not change the negative inotropic effect of rest-interval on contractions. The present results, also, suggest that the SR seems to play an important role in $\mathrm{Ca}^{2+}$ cycling in frog myocardium and hence support the force developed at low rates of stimulation $(0.003 \mathrm{~Hz})$. This is because verapanil combined together with adrenaline removed the negative inotropic effect of rest-interval on contractions. The action of this interaction is still unknown.

\section{REFERENCES}

Anderson, M.E.; Fox, I.J.; Swayze, C.R. and Donaldson, S.K. (1989): Frog ventricle: Participation of SR in excitation-contraction coupling. Am. J. Physiol. 256 (Heart Circ. Physiol. 25): H432439.

Boller, M. and Bott, L. (1989): $\beta$ Adrenergic modulation of transient inward current in guinea pig cardiac myocytes. Pflügers Arch. $415: 276-288$

Brückner, R.; Mügge, A and Scholz, H. (1985): Existence and functional role of $\alpha_{1}$-adrenoceptors in the mammalian heart. J. Mol. Cell cordial. 17:639-645.

Devlin, C.L. (1993): Acetylcholine-induced contraction in holothurian (Isostichopus badionotus) smooth muscle are blocked by the calcium antagonists, diltiazem and verapamil-Comp. Biochem. Physiol. 106C, No. 2: $573-577$.

Drake-Holland, A. J.; Herbaczynska-cedro, K.: Seed, W. A. and Noble M. I. M. (1992): Effect of adrenaline on cardiac force-interval relationship. Cardiovas. Res. 26: 496-501.

Drake-Holland, A.J.; Sitsapesan, R.; Herbaczynska-cedro, K.; Seed, W.A. and Noble, M.I.M. (1992): Effect of adrenaline on cardiac force-interval relationship. Cardiovas, Res. 26: 496-501.

Driedzic, W.R. and Gesser, H. (1985): $\mathrm{Ca}^{2+}$ protection from the negative inotropic effect of contraction frequency on telcost hearts. J. Comp. Physiol. B 156: 135-142.

Driedzic; W.R. and Gesser, H. (1994): Energy metabolism and contractility in ectothermic vertebrate hearts: hypoxia. acidosis and low temperaturc. Physiol. Rev. 74:221-258. 
El-Sayed, M.F. (1994a): Force, sarcoplasmic reticulum and potassium at different temperature in cardiac tissue of Clarias lazira. I Egypt. Ger. Soc. Zool. Vol. 15 (A), Comp. Physiol. $509-526$.

EI-Sayed, M.F. (1994b): The influence of temperature on force development and force-frequency relationships at increased extracellular calcium and potassium in the myocardium of Clarias lazira. J. Egypt. Ger. Soc. Zool. Vol. 15(A), Comparative Physiology. $259-279$.

EI-Sayed, M.F. (2000 a): Effects of adrenaline, caffeine and verapamil on the cardiac contractility after rest interval in teleosts and amphibians. J. Assiut Vet. Med. 84: $328-348$.

El-Sayed, M.F. (2000 b): Role of calcium channel in the development of cardiac force in the Clarias lazira: Effect of verapamil and caffeine. J. Ligypt. Ger. Soc. Zool. Vol, 31 (A) Comp. Physiol. $111-124$

El-Sayed, MF and Gesser, H (1989): Sarcoplasmic reticulum potassium and cardiac force in rainbow trout and plaice. Am. J. Physiol. 257: R599-R 604

(rebella, G. (1978): Inpocketing of the cell membrane (Caveolae) in the rat myocardium. J. Ultrastruct. Res. 65: 135-147.

Gesser, H. (I996): Cardiac force-interval relationship, adrenaline and sarcoplasmic reticulum in rainbow trout. J. Comp. Physiol. B 166: $278-285$

Godfraind, T. (1987): Classification of calcium antagonists. Am. J. Cardial. 59:11B - $23 \mathrm{~B}$

Hilgemann, D.W.: Delay, $M$. and Longer, G.A. (1983): Activation dependent cumulative depletions of extracellular free calcium in guinea pig atrium measured with Antipyralazo III and tetramethylmurexide-Circ. Res. 53-779-793.

Jones, L.R.; Besch, H.R. Sutko, J.L. and Willerson, J.T. (I979). Ryanodine-induced stimulation of net $\mathrm{Ca}^{2+}$ uptake by cardiac sarcoplasmic reticulum vesicles. J. Pharmacol. Exp. Ther. 209: $48-55$.

Keen, J.E.: Farrell, A.P., Tibbits, G.F. and Brill, R.W. (I992): Cardiac Physiology in tunas. Fffects of ryanodine, Calcium and adrenaline on force-frequency relationships in atrial strips from Skipjack tuna, Katsuwonus pelamis. Gen. J. Zool. 70: 1211 1217. 
Klitzner. T. and Morad, M. (1983): Excitation-contraction coupling in frog ventricle. Possible $\mathrm{Ca}^{2+}$ transport mechanism. Pflügers Arch. 398: 274-283.

Lennard, R. and Huddart, H. (1989): Purinergic modulation of cardiac activity in the flounder during hypoxic stress. I. Comp. Physiol. 159 B: $105-113$.

Macleod, K.T. and Bers, M.D. (1987): Effects of rest duration and ryanodine on changes of extracellular $\left[\mathrm{Ca}^{2+}\right]$ in cardiac muscle from rabbits. Am. J. Physiol. 253 (Cell Physiol. 22): C 398 C407.

Meissner, $G$. (1986): Ryanodine activation and inhibition of the $\mathrm{Ca}^{2+}$ release channel of sarcoplasmic reticulum. J. Biol. Chem. 261: 6300-6306.

Morad, M. and Cleemann, L. (1987): Role of $\mathrm{Ca}^{2+}$ channcl in development of tension in heart muscle. J. Molec. Cell. Cordial. 19: $527-553$

Morad, M. and Goldman, Y. (1973): Excitation-contraction coupling in heart muscle. Membrane control of development of tension. Prog. Biophys. Mol. Biol. 27:257-313.

Murad, F, (1991): Agents used in the treatment of angina, organic nitrates, calcium channel blockers and beta adrenergic antagonists. In Pharmacological Basis of therapeutics (Edited by Goodman A. G., Rall T. WE., Nies A. S, and Taylor P.). PP. $724-873$. Pergamon Press. New York.

Niedergerke, R. and Page, S.G. (1989): Receptor-Controlled Calcium discharge in frog heart cells. Q. J. Exp. Physiol. 74: 987-1002.

Pecker, M.S.; IM, W.B.; Soon, J.K and Lee, C.O. (1986): Effect of norepinephrine and cyclic AMP on intracellular sodium ion activity and contractile force in canine cardiac purkinje fibers. Circ. Res. 59: $390-397$.

Ponce-Hornos, J. E; ; Musi, E.A. and Bonazzola, P. (1990): Role of extraccllular calcium on heart muscle energectics. Effects of verapamil. Am. J. Physiol. 258 (Heart Circ. Physiol. 27): H64 $\mathrm{H} 72$.

Reuter, H. (1983): Calcium channel modulation by enzymes and drugs. Nature 301: $569-574$

Stemmer, $P$. and Akera, T. (1986): Concealed Positive force-frequency relationships in rat and mouse cardiac muscle revealed by ryanodine. Am. J. Physiol. 251 (Heart Circ. Physiol. 20): It $1106-\mathrm{H} 1110$. 
Sutko, J.L. and Kenyon, J.L. (1983): Ryanodine modification of cardiac muscle responses to potassium-free solutions. J, Gen. Physiol. 82: $385-404$.

Tibbits, G.F.; Hove-Madsen, L. and Bers, D.M. (199l): Calcium transport and the regulation of cardiac contractility in teleosts: a comparison with higher vertcbrate Can. J. Zool. 69: 2014-2019.

Tibbits, G.F.; Kashihara, H.; Thomas, M.J.; Keen, J.E. and Farrell, A.P. (1990): $\mathrm{Ca}^{2+}$ transport in myocardial sarcolemma from rainbow trout. Am. J. Physiol. 259: R 453 - R 460.

Vornanen, M. (1989): Regulation of contractility of the fish (Carassius carassius L.) heart ventricle. Comp. Biochem. Physiol. 94C: $477-483$. 
The influence of adrenaline, verapamil, adrenaline+ verapamil, verapamil tadrenaline and $2.5 \mathrm{mM}$ extracellular calcium on the cardiac force, the rate of contraction, (df/dt), the rate of relaxation (-df//fdt) and the time to peak ension (TPT) in the heart of the catfish $(A)$ and fog $(B)$.

Table A: Fishes

\begin{tabular}{|c|c|c|c|c|c|c|c|c|c|c|}
\hline Pasa & Cont & $\underset{\mathrm{Ca}^{2+}}{\text { Cont }}+$ & Adr. & $\begin{array}{c}\mathrm{Adr}^{+}+ \\
\mathrm{Ca}^{\mathrm{i}^{+}}\end{array}$ & Ver- & $\begin{array}{l}\mathrm{Verr}^{2}+ \\
\mathrm{Ca}^{2-}\end{array}$ & $\begin{array}{l}\mathrm{Add},+ \\
\mathrm{Ver}+ \\
\mathrm{Ca}^{2+} \\
\end{array}$ & 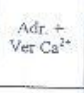 & $\begin{array}{l}\text { Ver. + } \\
\text { Adf. }\end{array}$ & $\begin{array}{l}\mathrm{Ver}+ \\
\mathrm{Ad}^{2+} \\
\mathrm{Ca}^{2}\end{array}$ \\
\hline Force & $16 \pm 3.6$ & {$[20 \pm 2.7$} & $21 \pm 2$ & $153 \pm 16$ & $-14 \div 2$ & $111 \pm 2$ & $23 \pm t$ & $112 \pm 2.7$ & $64 \pm 14$ & $150 \div 18$ \\
\hline$d f / d t$ & $14 \pm 1.7$ & $115 \pm 2.4$ & $20 \pm 5.2$ & $144 \pm 16$ & $.23+4$ & $115 \pm 1$ & $26 \pm 4.3$ & $104+3$ & $50 \pm 1.3$ & $136 \pm 20$ \\
\hline$-\mathrm{df} / \mathrm{dt}$ & $14+1.1$ & $103 \div 7$ & $23 \div 8.1$ & $134+5.2$ & $-28+3.4$ & $121 \leftleftarrows 2$ & $19 \pm 7$ & $102+5.6$ & $35 \pm 7.1$ & $116 \pm 8$ \\
\hline TPT & $4 \pm 6$ & $100 \pm 0.7$ & $s+5.3$ & $79 \pm 1.1$ & $8 \pm 0.7$ & $115+1.1$ & $9+1$ & $82 \pm 1.5$ & $18 \pm 7.3$ & $84+13$ \\
\hline
\end{tabular}

Table B: Toad

\begin{tabular}{|c|c|c|c|c|c|c|c|c|c|c|}
\hline Para: & Cont: & $\underset{\mathrm{Ca}^{3+}}{\operatorname{Cont}}+$ & Adr. & $\underset{\mathrm{Ca}^{2+}+}{\mathrm{Ads}^{2+}}$ & Ver. & $\begin{array}{l}\mathrm{Ver}_{-}^{+}+ \\
\mathrm{Ca}^{2+}\end{array}$ & $\begin{array}{l}\mathrm{Adr}+ \\
\mathrm{Ver}+ \\
\mathrm{Ca}^{2+}\end{array}$ & $\begin{array}{l}\text { Adr, }+ \\
\text { Ver } \mathrm{Ca}^{2+}\end{array}$ & $\begin{array}{l}\text { Ver.+ } \\
\text { Adr. }\end{array}$ & $\begin{array}{l}\text { Ver }+ \\
\mathrm{Ad}^{+{ }^{+}} \\
\mathrm{Ca}^{2^{+}}\end{array}$ \\
\hline Force & $-38 \pm 5.7$ & {$[29 \pm 14$} & $-27 \pm 2.1$ & $159 \pm 15$ & $32+4$ & $96 \pm 8$ & $-44 \pm 5$ & $119+14$ & $27 \pm 2.2$ & $13 !+2.4$ \\
\hline $\mathrm{df} / \mathrm{dt}$ & $-34 \div 2.6$ & $116 \pm 4.9$ & $-4 \pm 2,8$ & $142 \pm 4,3$ & $-29+3$ & $108 \pm 12$ & $-31 \pm 6.1$ & $119 \pm 12$ & $35 \pm 2$ & $136 \pm 4$ \\
\hline$-d f d t$ & $-25 \pm 1.1$ & $116 \pm 6.0$ & $-22 \pm 1.9$ & $|5| \pm 3.7$ & $-24 \pm 1.3$ & $96 \pm 14$ & $-3.4 \pm 1.3$ & $111 \pm 4$ & $38 \pm 4,5$ & $136 \pm 5.1$ \\
\hline TPR & $19 \pm 1.7$ & $10 \pm 7.5$ & $00 \div 0.0$ & 8014.4 & $.23 \pm 4$ & $56 \pm 4$ & $13 \pm 1.4$ & $87+1.4$ & $22 \pm 6$ & $98 \pm 5.6$ \\
\hline
\end{tabular}


Assiut Vet. Med. J. Vol. 45 No. 90, July 2001
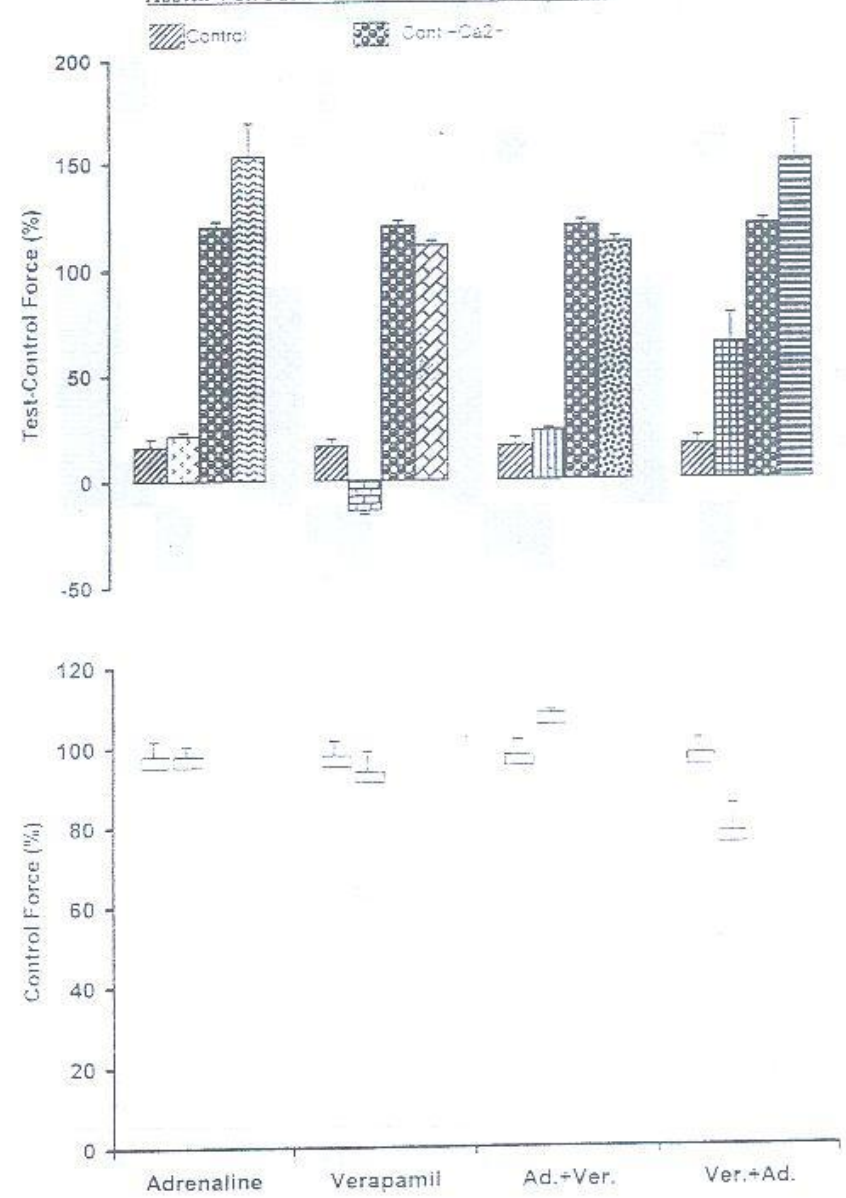

Fig . 1. Effects of adrenaline ( $)$. verapamil verapamil ( (DIfll), verapamil + adrenaline ( extracelluar calcium on the cardiac force develobed after 5 minutes of ras: in the catfish!Clarias garieninus $\quad r=f$ 


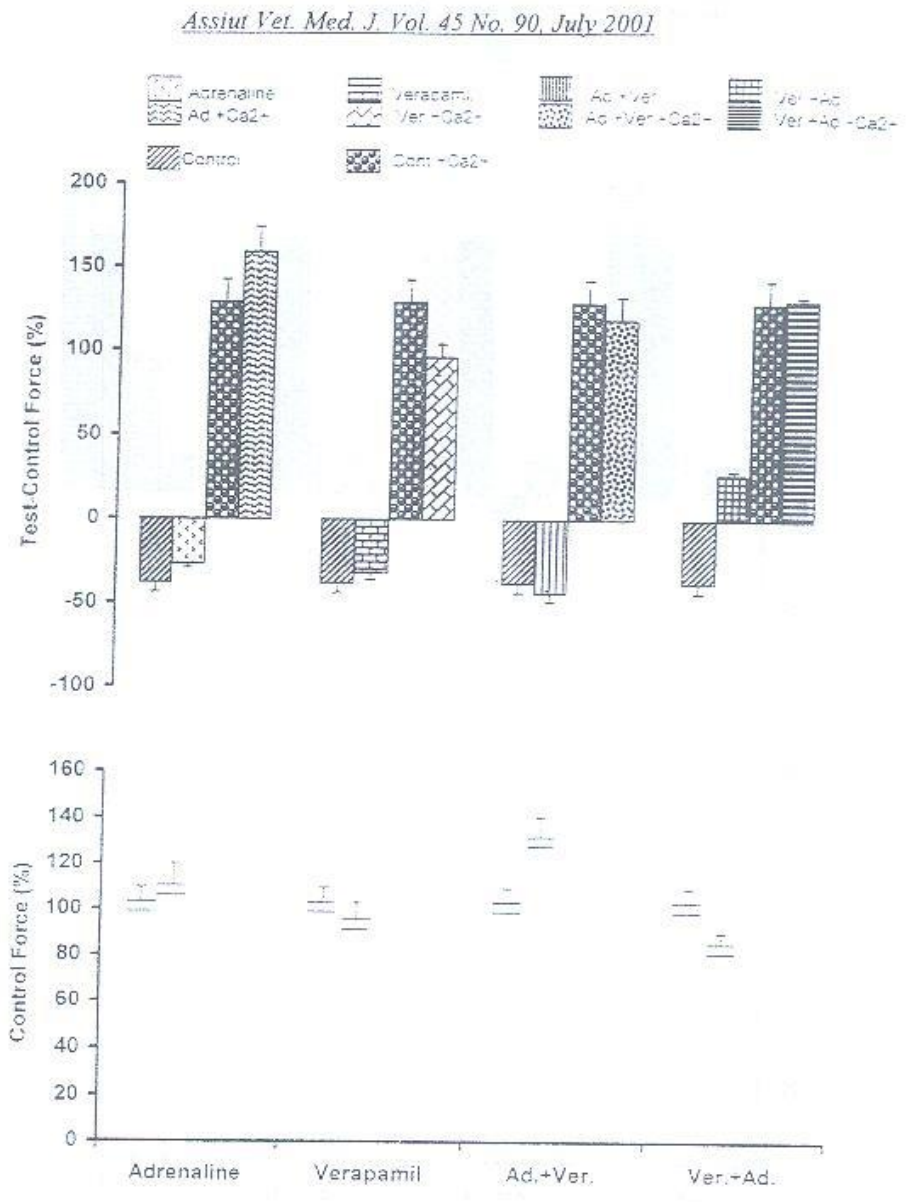

Fig . 2. Effects of adrenaline (-). verapamil ( $(\equiv)$, adrenaline -

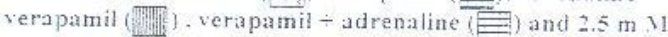
extracllular calcium on the cardiac force developed after 5 minutes of rest in the forg 1 Bufo regularis : heart. $n=6$. 
Assiut Vet. Med.J. Vol. 45 No. 90. July 2001
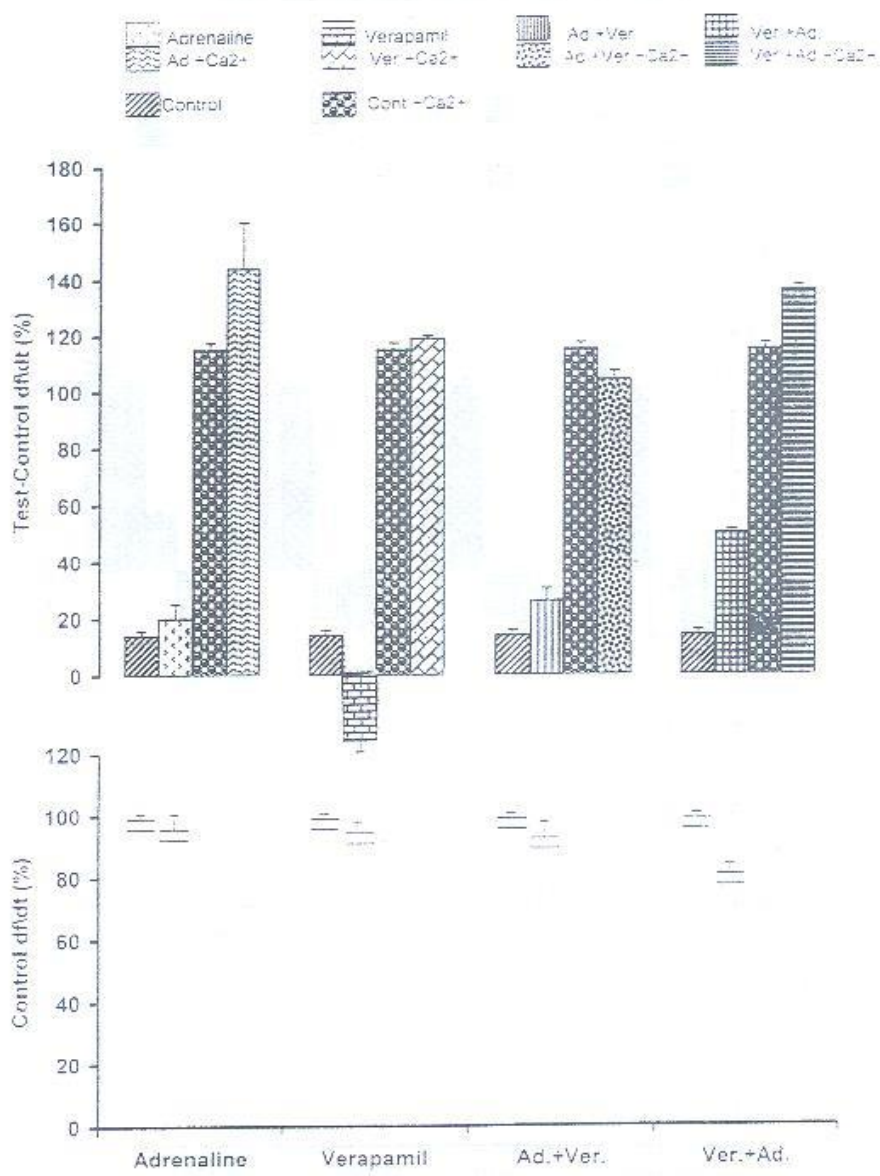

Fig. 3. Infuences of adrenaline - verapamil ( $\equiv$ ), adrenaline verapamil ( extracellular calcium on the rate of contraction,df $d t$. in the cardiac muscle of the catfish (Ciarias gariepinus after 5 minutes of rest $r=t$ 
4ssiuf Vet. Med.J. Vol 45 No. 90, July $200 \mathrm{~J}$

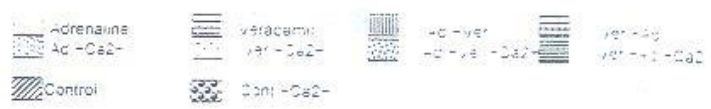
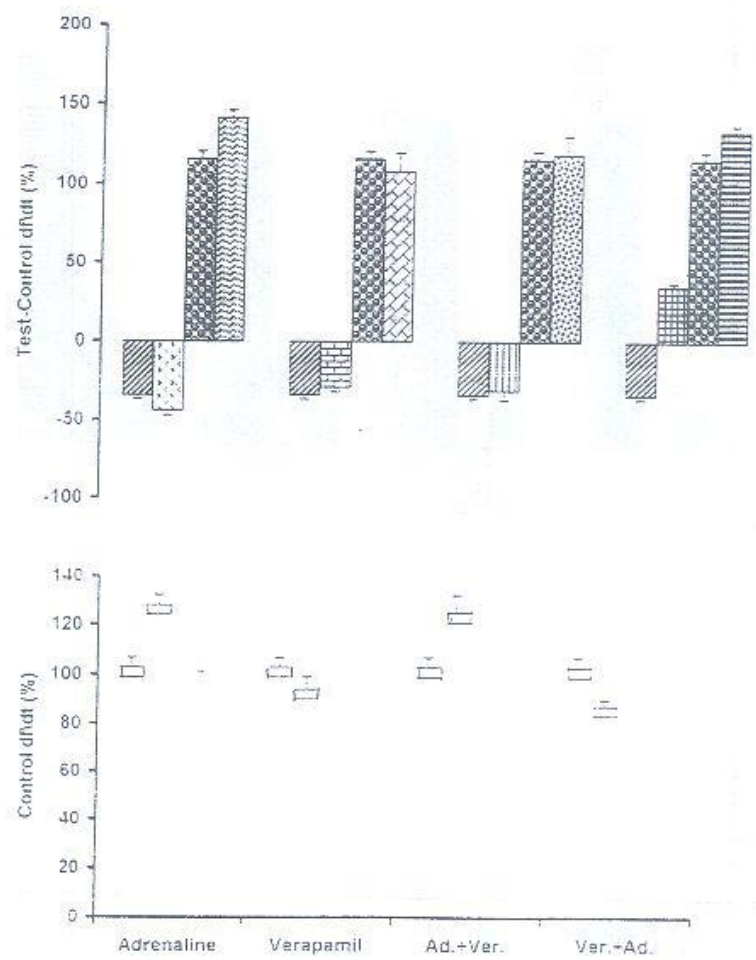

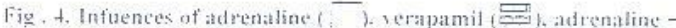

verapanail (

exracellular calcium on the rate of contraction. aff dt. in the

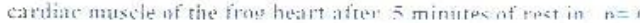




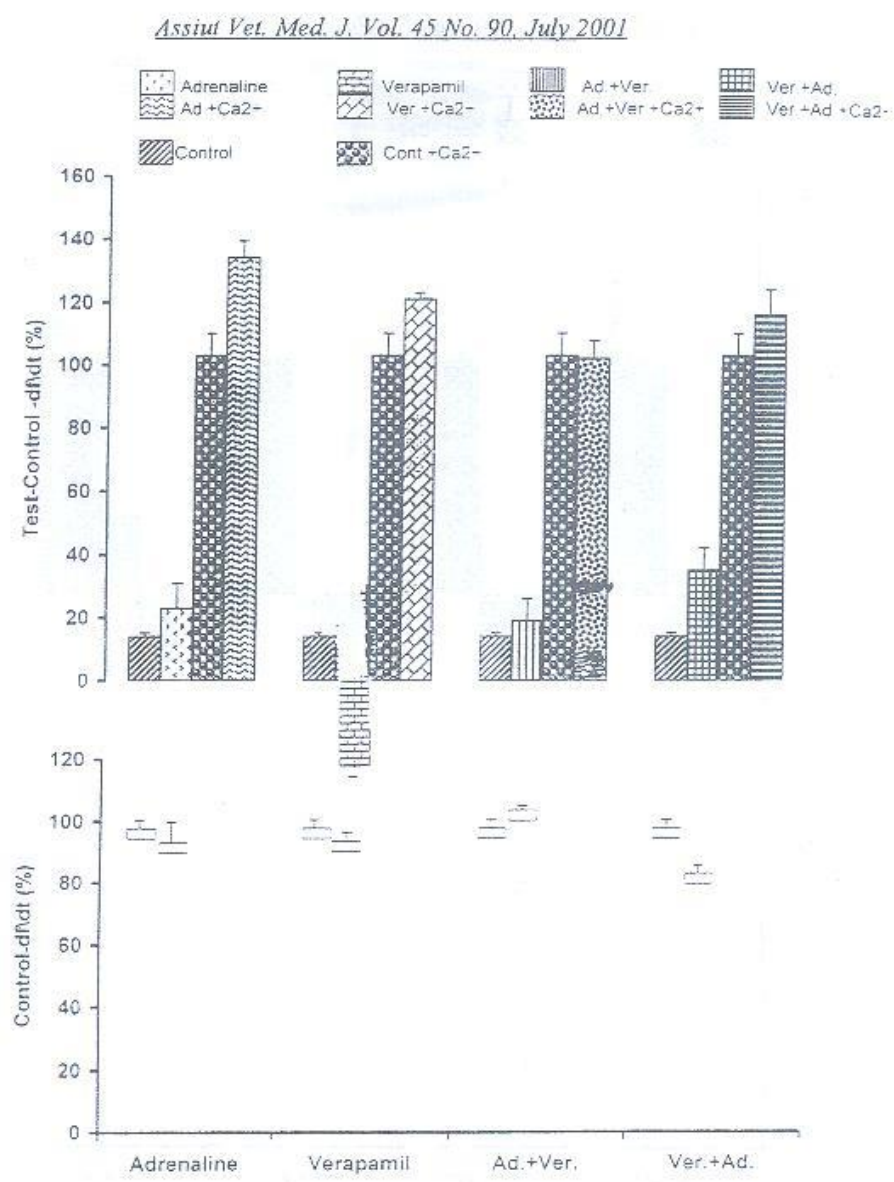

Fig. 5. Infuences of adrenaline $(\overline{3})$, verapamil ( verapamil ( extracellular calcium on the rate of relaxation .-df/dt, in the cardiac muscle of the catfish(Clarias gariepinus) after 5 minutes of rest. $\mathrm{n}=6$ 
Assiut Vet. Med.J. Vol. 45 No 90 . July 2001

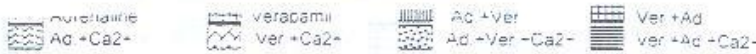

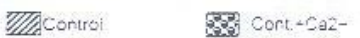
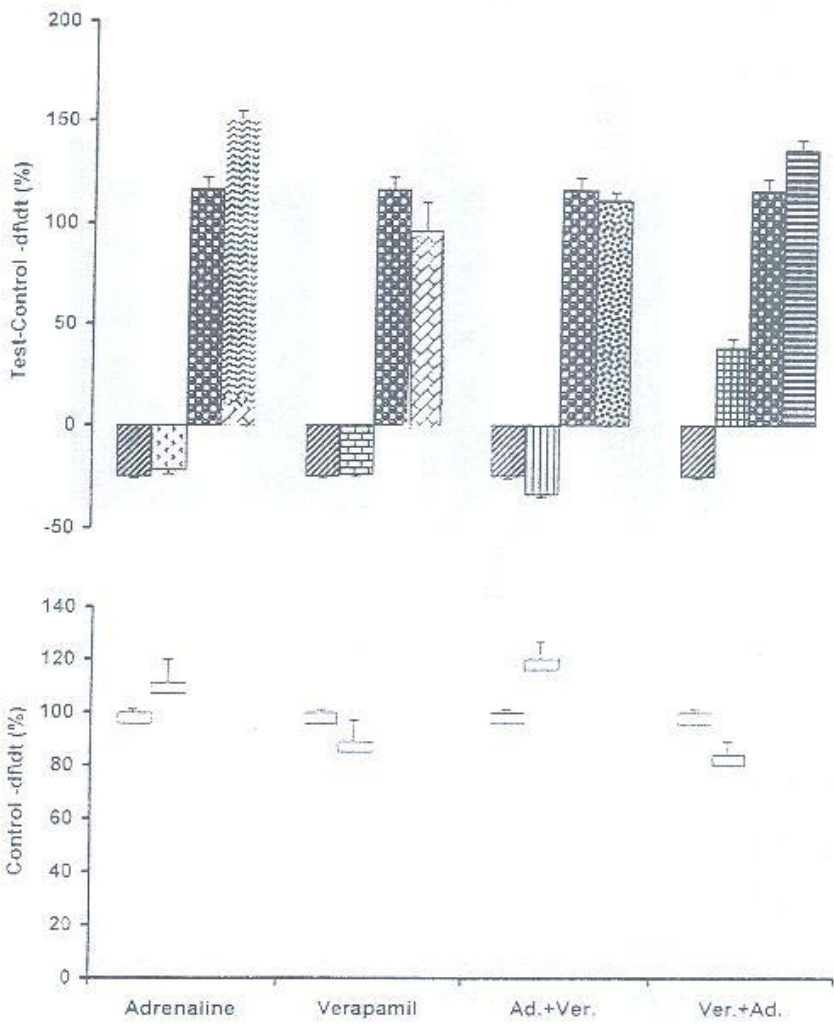

Fig. 6. Infuences of adrenaline ( verapamil ( $\Xi$ ), adrenaline verapamil (䡒), verapamil + adrenaline ( extracellular calcium on the rate of relaxation, -df/dt, in the heart of frog after 5 minutes of rest in , $n=6$. 
Assiut Vet. Med. J. Vol. 45 No. 90. July 2001
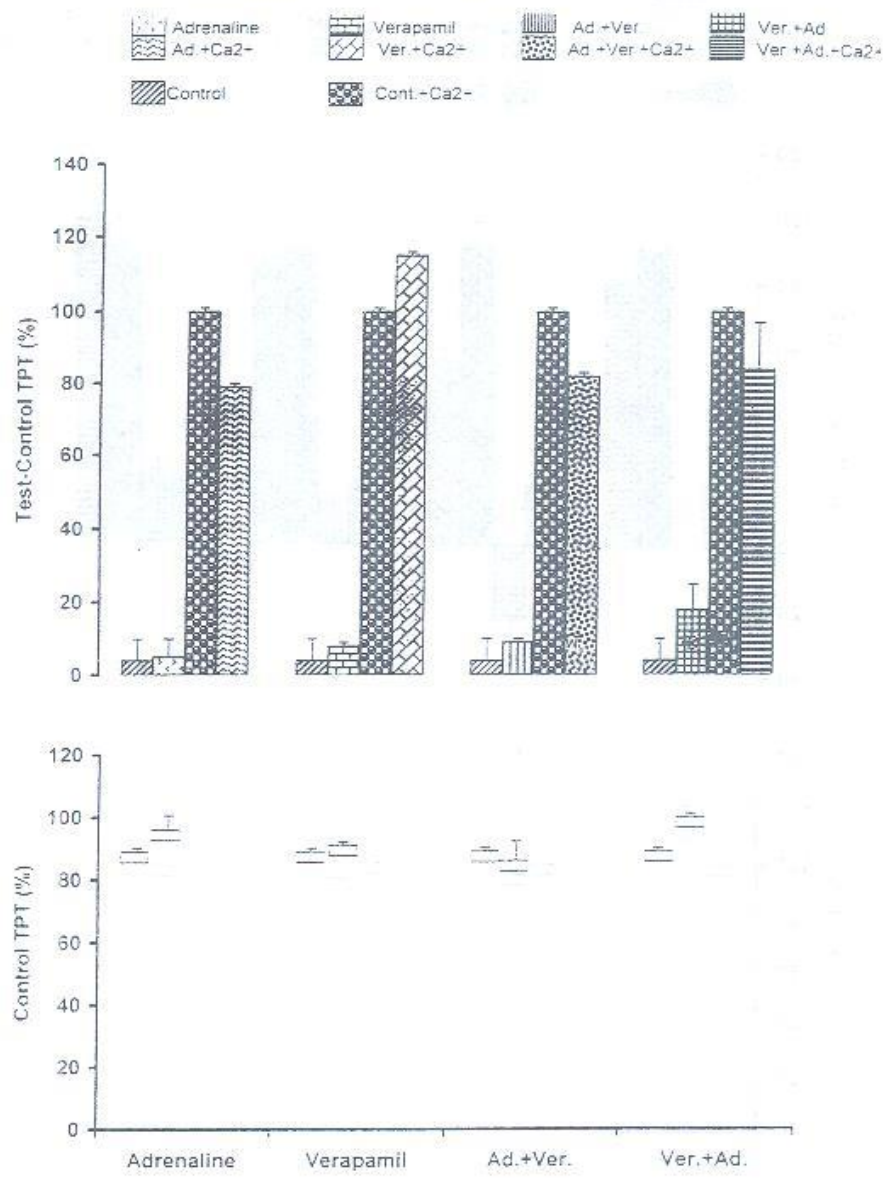

Fig. 7. Infuences of adrenaline ( $\square$, verapamil ( $)$, adrenaline verapamil ( $[$ ) verapamil + adrenaline ( ) and $2.5 \mathrm{~m} \mathrm{M}$ extracellular calcium on the time to peak tension (TPT) in the mvocardium of the catfish (Clarias gariepinus) after 5 minutes of rest in $n=6$. 
A.ssiut Vet. Med. J. Vol. 45 No. 90, July 2001

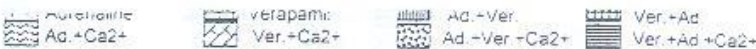

MCentrol
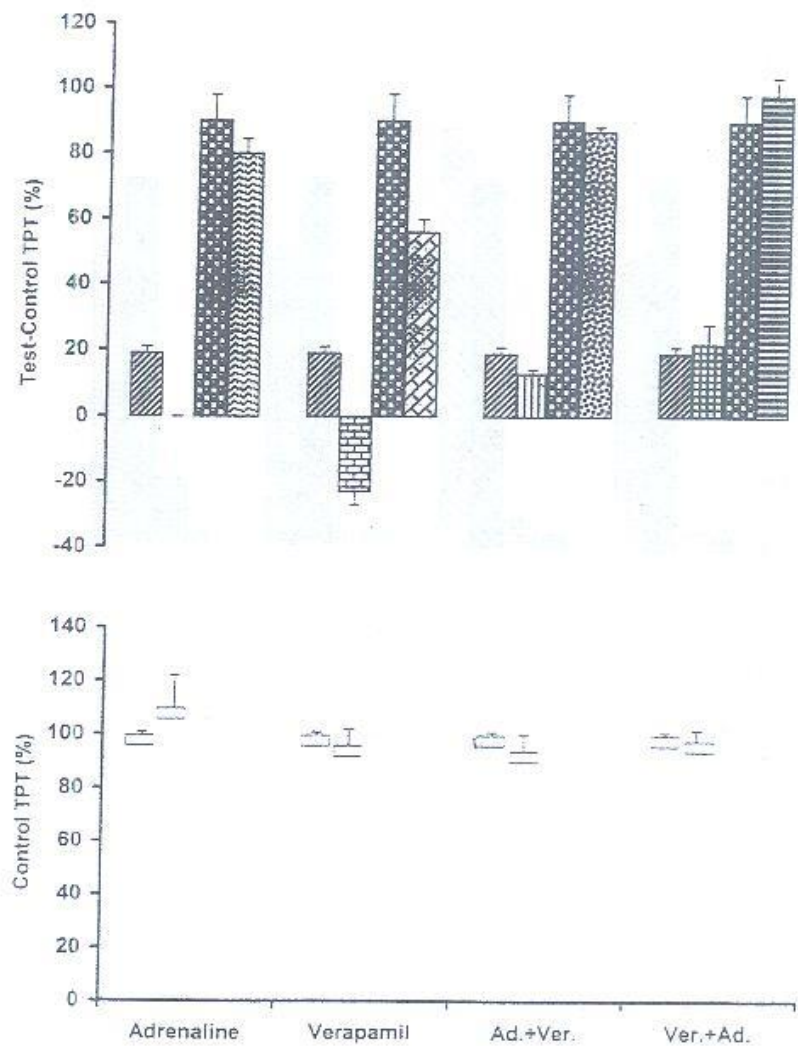

Fig . 8. Infuences of adrenaline ( 6 , verapamil (

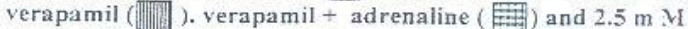
extracellular calcium on the time to peak tension (TPT) in the myocardium of the frog after 5 minutes of rest in . $n=5$. 